\title{
Para além da deliberação? APONTAMENTOS SOBRE A NORMATIVIDADE DA TEORIA PÓS-ESTRUTURALISTA DA DEMOCRACIA RADICAL
}

\author{
Daniel de Mendonça ${ }^{1}$
}

\begin{abstract}
Resumo
0 presente artigo tem por objetivo apresentar e discutir - no âmbito das teorias pós-estruturalistas da democracia radical, sobretudo aquelas identificadas com a "teoria do discurso da Escola de Essex" - o recente esforço no sentido de reduzir o que os próprios autores admitem ser um déficit normativo em relação a suas discussões contemporâneas acerca da democracia. Mais concretamente, este trabalho tem como foco dois modelos político-normativos que têm sido levados a efeito a partir desta tradição teórica, mormente os trabalhos de Chantal Mouffe e de Aletta Norval. 0 intuito é apontar os eventuais avanços obtidos pela vertente pós-estruturalista, modelo teórico alternativo ao enfoque deliberativo no debate democrático contemporâneo.
\end{abstract}

Palavras-chave: Democracia deliberativa. Pós-Estruturalismo. Teoria do discurso. Normatividade.

${ }^{1}$ Professor adjunto no Programa de Pós-Graduação em Ciência Política da Universidade Federal de Pelotas (UFPel). End. Eletrônico: ddmendonca@gmail.com 


\title{
Beyond Deliberation? Considerations about THE NORMATIVITY OF THE POST-STRUCTURALIST THEORY OF RADICAL DEMOCRACY
}

\begin{abstract}
The present article has the objective of presenting and discussing - in the sphere of post-structuralist theories of radical democracy, mainly those identified through the "Theory of speech of the Essex School" - the recent effort in order to reduce what the authors themselves admit to be a normative deficit in relation to their contemporary discussions about democracy. More concretely, this work focuses on two political-normative models that have arisen from this theoretical tradition, especially the works of Chantal Mouffe and Aletta Norval. The aim is to point out the eventual advances obtained through post-structuralism, an alternative theoretical model to the deliberative focus on the contemporary democratic debate.
\end{abstract}

Keywords: Deliberative democracy. Post-structuralism. Theory of speech. Normativity.

\section{INTRODUÇÃo}

0

presente trabalho tem por objetivo explorar as potencialidades normativas presentes nas abordagens pós-estruturalistas da política, mais especificamente as análises de Chantal Mouffe e de Aletta Norval. Ambas as autoras poderiam ser grosso modo consideradas como representantes da teoria do discurso da Escola de Essex, vertente teórica, cujo ponto de partida pode ser atribuído ao lançamento, por Ernesto Laclau e Chantal Mouffe, da obra Hegemony and Socialist Strategy em 1985.

Outros dois pontos de convergência parecem importantes ser levantados em relação às referidas autoras. Primeiramente, ambas promovem uma discussão crítica em relação aos postulados da teoria deliberativa da democracia, sobretudo de vertente habermasiana. Ligado a este primeiro ponto, elas também propõem elementos normativos visando a um aumento na qualidade do debate democrático. Este segundo ponto é particularmente interessante, pois propostas normativas são deficitárias ou muito restritas para esta escola teórica. Assim, quase que contrariando esta "regra" nas formulações pós-estruturalistas da política, Mouffe e Norval dedicam-se a pensar cenários políticos que qualifiquem as experiências democráticas. 
Neste artigo, portanto, as discussões sobre a democracia agonística de Mouffe e a democracia aversiva de Norval terão centralidade. Inicialmente, será tratada a proposta de Mouffe. Esta, apesar de uma importante visão acerca da essência do político, não parece capaz de ir além da enunciação de um princípio democrático agonístico, longe, assim, de poder ser entendido como um modelo agonístico, como a própria autora nomeia seu esforço. A seguir, a proposta de Norval será apresentada a partir do seu último trabalho, publicado em 2007, intitulado Aversive Democracy. Ver-se-á que o esforço de Norval vai muito além se comparado com o de Mouffe, sobretudo tendo em vista que ele é uma clara tentativa de articular, ao mesmo tempo, pressupostos ontológicos do político, presentes na tradição pós-estruturalista, com o esforço de construção de espaços institucionais, presente nos esforços deliberativos.

\section{Chantal Mouffe E A CRÍTICA À TRADIÇÃo DELIBERATIVA}

0 diálogo que Chantal Mouffe estabelece com a tradição deliberativa já ocorre há algum tempo. Desde o seu primeiro trabalho posterior a Hegemony and Socialist Strategy, O Regresso do Político (1993), passando por The Democratic Paradox (2000), e On the Political (2005), a autora vem lendo criticamente as formulações de John Rawls e Jürgen Habermas. Para além das críticas individualizadas a tais autores, as quais não serão aqui abordadas, Mouffe, em linhas gerais, opõe suas críticas a dois postulados deliberativos abaixo resumidos:

a) A busca para assegurar o vínculo entre a democracia e o liberalismo, refutando todas as tentativas teóricas que insistem na natureza contraditória da democracia liberal. Ambos os autores, buscam conciliar, em última análise, segundo Mouffe (2003), a liberdade dos antigos com a liberdade dos modernos.

b) A crença compartilhada em relação à produção de uma forma de racionalidade que não seja meramente instrumental, mas que se afirme como uma dimensão normativa do social.

Os postulados acima estão relacionados e, portanto, serão tratados conjuntamente. No entanto, um possível ponto de partida para o argumento de Mouffe (2003) pode ser a crítica ao que ela denomina de o "modelo do consenso democrático" que está presente tanto na proposta de terceira via, formulada por Anthony Giddens (MOUFFE, 2003, 2005), como na tradição da democracia deliberativa de Rawls e Habermas. Segundo a autora, a defesa que esses teóricos fazem da possibilidade do consenso como forma de conceber a boa democracia, 
a sociedade bem-ordenada, denota uma incapacidade de compreensão da própria política democrática, sobretudo, contemporânea, uma vez que a ênfase no consenso sustenta-se na crença de que o antagonismo pode ser efetivamente erradicado do horizonte da política. Para Mouffe, o antagonismo não é um mero momento político, tido pelos enfoques deliberativos como negativo, pois excludente, mas a própria lógica de constituição de qualquer relação política entre identidades.

Conforme a autora, portanto, o próprio consenso é um desses arranjos históricos e contingentes fruto de um tipo de formulação política que busca hegemonizar seus conteúdos socialmente. Dito de outra forma: para além de considerar o consenso uma solução que possa abranger todos os interesses, sua proposição já é em si uma imposição política excludente, pois desconsidera outras formas de tomadas de decisão, outras maneiras de argumentação democrática, pois as relega à condição de formulações políticas inferiores.

Ligada à idéia do consenso, Mouffe critica a tentativa comum de Rawls e de Habermas de conciliar a liberdade dos antigos (democracia) com a liberdade dos modernos (liberalismo). Segundo ela, Rawls e Habermas concordam num ponto chave:

[...] na crença de que através de adequados procedimentos deliberativos seria possível superar o conflito entre os direitos individuais e as liberdades, por um lado, e as demandas por igualdade e por participação popular, por outro (MOUFFE, 2003, p. 25).

Contrariamente, para Mouffe, nenhuma das duas propostas consegue conciliar democracia e liberalismo, uma vez que ambas as tradições são partes constituintes do que a autora tem chamado de o "paradoxo da democracia moderna", fundado justamente na sempre frustrada tentativa de conciliação da liberdade dos antigos com a liberdade dos modernos. Por certo, é conditio sine qua non para a democracia a convivência de ambos os institutos, mas tal convivência sempre será imperfeita, um paradoxo sempre presente. Em outras palavras: a autora argumenta que a democracia liberal contemporânea resulta na articulação contingente e precária dessas duas lógicas que são, em si, incompatíveis e que todo esforço de conciliação entre ambas resultará sempre imperfeito. Isto tendo em vista que:

Por um lado, temos a tradição liberal constituída pelo império da lei, a defesa dos direitos humanos e o respeito à liberdade individual; por outro, a tradição democrática, cujas idéias principais são as de igualdade, identidade entre 
governantes e governados e soberania popular. Não existe uma relação necessária entre estas duas tradições distintas, somente uma imbricação histórica contingente (MOUFFE, 2003, p. 20).

Mouffe aborda ainda que a busca da conciliação entre tais gramáticas distintas, ou seja, a liberdade dos antigos e a liberdade dos modernos, apresenta outro ponto em comum para os teóricos deliberativos: a tentativa do estabelecimento de uma solução racional para as questões públicas. Opondo-se a tal perspectiva, a autora defende que qualquer projeto que busque uma solução racional para a questão da justiça pode ser, no limite, perigoso. Perigoso, porque a solução racional pode sugerir uma sutura (fechamento) do espaço que separa a justiça do direito, justamente o espaço constitutivo da democracia moderna. Entendendo-se aqui que esta sutura, que pode proporcionar um projeto racionalista é, de fato, impossível, uma vez que o social e suas lutas são de múltiplas possibilidades e qualquer tentativa de um arranjo racional não passa de mais uma tentativa de suturar o espaço social: de vê-lo como uma totalidade fragmentada à espera de sua recomposição. Em verdade, não há nada capaz de compor uma sociedade que por essência não se presta à composição com vistas a sua reconciliação a partir de uma melhor forma de governo, ou de uma melhor forma de tomada de decisões públicas. Qualquer projeto político assume, conforme a perspectiva de Mouffe, a condição de uma representação precária e contingente, pois que é incapaz de dominar o campo social que sempre o transborda. A luta política é, segundo a autora, em última análise, infinita.

Assim, a decisão racional, como modus faciendi da política, ao contrário do que ela própria parece sugerir, seria tão-somente o resultado de uma luta, a qual, por exemplo, a racionalidade comunicativa não passaria de uma solução hegemonizada definida por uma contingência histórica falível e não propriamente pactuada a partir de pressupostos tidos como razoáveis ou mesmo minimamente desejáveis por uma série de identidades. Teríamos aqui uma operação hegemônica com a sua consequência, esta sim lógica de se supor: a da existência de uma contrahegemonia. Desta forma, conforme Mouffe (2003, p. 48), devemos renunciar à idéia de um consenso político "racional" entendido por ela como "um consenso que não esteja baseado em nenhuma forma de exclusão". A exclusão é parte da dimensão antagônica da política, constitutiva das relações sociais. A racionalidade é tão-somente mais um tipo de exclusão: Em suas palavras: 
Apresentar as instituições da democracia liberal como o resultado de uma racionalidade puramente deliberativa é reificá-las e convertê-las em algo impossível de transformar. É negar o fato de que, igual a qualquer outro regime, a moderna democracia pluralista constitui um sistema de relações de poder e torna o questionamento destas formas de poder algo ilegítimo (MOUFFE, 2003, p. 48).

Assim, para Mouffe, a questão do poder é central e constitutiva das relações sociais. A autora argumenta que, a despeito da busca de uma solução racional às questões públicas, o fechamento a outras racionalidades ou mesmo às paixões políticas reflete-se tão-somente em mais uma forma de poder. Ela critica o modelo deliberativo, o qual parte do pressuposto de que os indivíduos são considerados anteriores e não propriamente constituídos pela sociedade; que são portadores de direitos naturais e que lhes é possível compartilhar uma mesma racionalidade operativa para as questões políticas, independentemente de suas histórias de vida, de aspectos culturais, étnicos, religiosos, como se estes fossem idiossincrasias que deveriam permanecer no mundo privado, como se não fossem relevantes para as suas próprias ações políticas, para as suas próprias concepções ideológicas de mundo. Em última análise, o modelo racional comunicativo reifica uma forma política oriunda da tradição ocidental que abstrai paixões e afetos como formas também legítimas de pensar o político. Em oposição, Mouffe (2003, p. 49) argumenta:

Diferentemente de outros projetos de democracia radical ou participativa informados por um marco racionalista, a democracia radical e plural rechaça a própria possibilidade de uma esfera pública de argumento racional não excludente em que seja possível alcançar um consenso não coercitivo. Ao mostrar que dito consenso é uma impossibilidade conceitual, não põe em perigo o ideal democrático, como alguns argumentariam. Ao contrário, protege a democracia pluralista de qualquer tentativa de fechamento. De fato, essa negativa constitui uma importante garantia de que se manterá viva a dinâmica do processo democrático.

Desta feita, a importância do não-fechamento da democracia pluralista deve ser aqui entendida como a sua própria possibilidade de permanência como regime que visa a dar voz e reconhecimento ao maior número possível de identidades. Prever a inclusão e a exclusão de diferenças não é, em si, excluir, mas ter a clareza de que qualquer arranjo político, no limite, é excludente, inclusive 0 modelo deliberativo, o qual parece excluir qualquer forma de manifestação política 
que não seja informada a partir de parâmetros da racionalidade comunicativa. É não deixar de fora do horizonte democrático o antagonismo, como dimensão ontológica do político, inerradicável, portanto. Segundo Mouffe (2003, p. 50): "em uma organização política democrática, os conflitos e os confrontos, longe de serem sinais de imperfeição, indicam que a democracia está viva e encontra-se habitada pelo pluralismo". Conflitos existem e podem oxigenar a democracia, desde que mediados por princípios democráticos, no dizer de Mouffe, de um pluralismo democrático agonístico.

\section{UM MODELO OU UM MERAMENTE PRINCÍPIOAGONÍSTICO?}

Apresentada a crítica de Mouffe à tradição deliberativa, a partir de agora, serão apresentados os aspectos constituidores da teoria democrática radical e plural, no sentido do que a autora tem chamado de o "modelo agonístico da democracia". Entretanto, sustenta-se aqui, contrariamente à idéia de um "modelo", que a autora tem enunciado, na verdade, até o momento, tão-somente um princípio teórico norteador, sendo esta a sua principal limitação como uma teoria que se coloca como alternativa aos modelos de Rawls e Habermas.

Inicialmente, para caracterizar o modelo agonístico de Mouffe, é necessário fazer menção a dois aspectos ontológicos da política segundo a autora. Neste particular, para melhor compreender a natureza do político, é necessário levar em consideração o poder e o antagonismo. A idéia de poder, por um lado, pressupõe sempre relações desiguais que constituem o social. Já a idéia de antagonismo, pressupõe a incapacidade da completude identitária, constantemente marcada pela luta por posições e recursos de poder e de reconhecimento. Isso quer dizer que o poder não deve, em absoluto, ser entendido como algo dado a partir da luta entre identidades previamente constituídas, mas justamente como o elemento que constitui, que (re)semantiza suas próprias identidades e sentidos (MOUFFE, 2003). Desta forma, tem-se como essência do político uma incessante luta pelo poder sempre protagonizada por identidades que, tendo em vista os seus cortes antagônicos, nunca completam seus conteúdos. As consequências para a democracia, nesse sentido, não poderiam ser mais claras:

Se aceitarmos que as relações de poder são constitutivas do social, então a pergunta principal que devemos atentar para a política democrática não é a de como eliminar o poder, mas a de como constituir formas de poder mais compatíveis com os valores democráticos (MOUFFE, 2003, p. 113). 
Assim, deve-se ter claro que as relações sociais são essencialmente conflituosas e que todos os intentos de eliminar poder e antagonismo das mesmas, como parecem supor os modelos deliberativos, estão fadados ao fracasso. 0 que resulta importante para Mouffe, é a necessidade da construção de mecanismos institucionais que "domestiquem" as relações antagônicas entre identidades as quais buscam hegemonizar sentidos no espaço social, a partir de operações discursivas.

Nesse ponto, é salutar ressaltar a distinção entre as dimensões ontológica e ôntica presente no argumento de Mouffe para, a partir daí, estabelecer as bases para o seu pluralismo agonístico. Tal distinção é realizada desde a diferenciação entre a "política" e "o político", sendo a primeira aquela diretamente ligada às práticas políticas cotidianas, às instituições e às formas de organização das relações sociais. Assim, a "política" assume o caráter ôntico, o da política do dia-a-dia. Já "o político" representa a própria dimensão antagônica inerente às relações humanas, presentes em todas as práticas políticas, pois que é constitutiva das mesmas. Assim, "o político" está num plano ontológico, ou seja, como aquilo que está na essência, na constituição, na forma, portanto, refere-se a como as relações políticas, sem exceção, devem ser pensadas. Nesse sentido, qualquer modelo teórico-normativo, se tem por objetivo ser factível, deveria levar em consideração, no entendimento de Mouffe, não a erradicação das relações de conflito; pelo contrário, teria de prever formas de institucionalizá-las, uma vez que é impossível a superação das relações desiguais de poder e de antagonismo, visto que ambos são elementos ontológicos, presentes, portanto, em todas as relações políticas.

Assim, segundo Mouffe, o que é central para a política democrática, ou o que deveria ser, tendo em vista esta percepção ontológica do político, é a busca da construção de um modelo que faça com que os inimigos (em uma relação antagônica) deixem de ser percebidos como tais e, portanto, como aqueles que devam ser subsumidos, eliminados. É necessário que sejam buscados meios para transformar inimigos em adversários, o que, na concepção de Mouffe, produz importantes consequências. Um inimigo, como já referido, é alguém que deve ser destruído; é alguém com quem se estabelece uma relação antagônica no sentido mais estrito do termo. Um adversário, por outro lado, é aquele cuja posição política não se concorda; porém, o mesmo tem o direito de defendê-la e esse direito não deve ser questionado. Nesse sentido, Mouffe postula:

Introduzir a categoria do 'adversário' requer fazer mais completa a noção de antagonismo e distinguir duas formas diferentes nas quais pode surgir esse 
antagonismo, o antagonismo propriamente dito e o agonismo. 0 antagonismo é uma luta entre inimigos, já agonismo é uma luta entre adversários. Por conseguinte, podemos voltar a formular nosso problema dizendo que, visto da perspectiva do 'pluralismo agonístico', o objetivo da política democrática é transformar o antagonismo em agonismo (MOUFFE, 2003, p. 116).

Conforme Mouffe, uma diferença essencial da sua proposta teórica em relação aos modelos deliberativos é que, para o "pluralismo agonístico", o objetivo da política democrática não é a eliminação das paixões, dos próprios interesses da esfera pública para aí se buscar um consenso racional, mas justamente o contrário. É tarefa da democracia a construção de mecanismos que sejam capazes de mobilizar, de dar existência a tais paixões e interesses dentro de princípios e regras democráticas, ou seja, que se assegure a existência do conflito, que é inerradicável, ao mesmo tempo em que se busque a transformação dos inimigos em adversários dentro de regras estabelecidas pelo jogo democrático. Nas suas próprias palavras:

Uma democracia que funcione corretamente exige o vibrante enfrentamento das posições políticas democráticas. Se isso é omitido, existe o perigo de que esta confrontação democrática seja substituída por uma confrontação entre outras formas de identificação coletiva, como ocorre no caso da política de identidade. Uma excessiva ênfase no consenso, unida ao rechaço à confrontação, conduz à apatia e ao distanciamento com relação à participação política. Ainda pior, o resultado pode ser a cristalização das paixões coletivas em torno de questões que não podem ser resolvidas mediante um processo democrático e a explosão dos antagonismos pode deixar em pedaços os próprios fundamentos da civilidade (MOUFFE, 2003, p. 117).

Portanto, conforme Mouffe, o objetivo da democracia não deveria ser a busca de um consenso racional no âmbito de uma ou de várias esferas públicas. É importante dizer que a autora não nega a possibilidade de se alcançar consenso sobre determinadas questões e em determinados contextos, mas este será sempre um resultado contingente de uma hegemonia provisória acerca de uma questão. Ainda mais, para Mouffe, a defesa de que o poder possa ser substituído por um debate racional em que, a partir daí, se poderia chegar a algum tipo de legitimidade pública é uma ilusão que pode inclusive "pôr em perigo as instituições democráticas" (MOUFFE, 2003, p. 117). Isto porque toda a forma de poder, inclusive o consenso racional, pressupõe exclusões e a tentativa de uma sutura final do social, a qual parece propor o modelo deliberativo, impede que outras formas políticas tenham efeito. 
Um exemplo interessante de entendimento do pluralismo agonístico presente nas democracias modernas é trazido por Mouffe a partir da análise de Canetti em Crowds and Power, no momento em que este autor fala da natureza do sistema parlamentar. Segundo Canetti (1962), a democracia e o sistema parlamentar não devem ser vistos necessariamente como um estágio evolutivo da humanidade, uma vez que as partes em disputa renunciaram à guerra como forma de solução de seus impasses políticos. Os seres humanos não trocaram, portanto, a batalha campal por um meio racional de decisão, pela livre razão pública quando instituíram os parlamentos. Conforme Canetti, citado por Mouffe (2005, p. 23):

Ninguém nunca realmente acreditou que a decisão da maioria é necessariamente mais sábia por ter recebido o maior número de votos. É vontade contra vontade, como na guerra. Cada um está convencido que 0 direito e a razão estão do seu lado. A conviç̧ão vem facilmente e o propósito do partido é, precisamente, manter este desejo e esta convicção vivos. 0 membro de um partido que perdeu a votação aceita a decisão da maioria, não porque ele deixou de acreditar no seu próprio ponto de vista, mas simplesmente ele admite a derrota.

É a partir deste exemplo de Canetti que se passa aqui a estabelecer algumas críticas ao pluralismo agonístico de Mouffe. Resumindo os pontos fundamentais de sua perspectiva, tem-se que:

a) as relações de poder e de antagonismo são constituidoras de todas as relações políticas (dimensão ontológica);

b) existem duas dimensões ou dois níveis em que as questões políticas devem ser levadas em consideração: a política (dimensão ôntica) e o político (dimensão ontológica);

c) qualquer tentativa de estabelecer um consenso permanente acerca de questões públicas é, no limite, impossível, ou seja, este não passará de um arranjo hegemônico precário, histórico e contingente;

d) como as relações antagônicas perpassam todas as relações humanas, a tarefa da democracia contemporânea está em transformar as relações antagônicas stricto sensu, ou seja, entre inimigos que querem se destruir, em relações agônicas, entre adversários que lutam aceitando alguns parâmetros comuns na disputa. 
0 exemplo de Canetti ilustra muito bem a domesticação agonística de disputas sociais. 0 parlamento foi a arena concebida para os antes inimigos, agora adversários, fazerem valer seus interesses e paixões. A derrota não é vista como uma derrota final. Há sempre a possibilidade de uma nova disputa, de uma virada no jogo e isso é o que dá legitimidade ao sistema parlamentar. 0 que, contudo, ficam mantidas são as regras do jogo, sobretudo as que dizem respeito ao fato de que a vitória de um grupo, ou partido, deve ser reconhecida pelo outro, não no mérito, uma vez que a vitória não é fruto de um consenso entre as partes, ou mesmo de um convencimento racional de uma pela outra, mas pela forma como ela foi obtida, ou seja, pela maioria numérica dos votos de quem legitimamente está apto para decidir.

Mesmo considerando interessante o argumento de Mouffe, entende-se aqui que é difícil considerar o seu autodenominado "modelo" pluralista agonístico como efetivamente um modelo, ainda mais se comparado com os de Rawls e Habermas. Estes últimos apresentam seus modelos e os desenvolvem a partir de uma série de condições e de formas de execução. É possível ter um "aspecto visual" em suas propostas, pois, enfim, são realmente modelos políticos normativos. Isso não ocorre no caso de Mouffe e esse ponto parece ser o que mais fragiliza o seu argumento.

Apesar de o pluralismo agonístico já estar sendo apresentado pela autora desde o seu penúltimo livro, The Democratic Paradox, ela não avança muito além do que ela própria chama de transformar as relações antagônicas em agônicas num contexto político democrático sempre dominado pelas questões de poder e de antagonismo. Seu argumento desconstrutivista ao modelo deliberativo é importante, sem dúvida. Contudo, quando chega ao momento de ela própria exercer seu papel normativo, sua empresa emperra.

Assim, parece que a tarefa central do pluralismo agonístico de Mouffe é constituir-se de fato como um modelo teórico passível de ser testado. No entanto, até 0 momento restringe-se à desconstrução, aí sim, dos modelos deliberativos baseados no consenso. Mouffe ainda está no nível da enunciação de princípios, os quais são de duas ordens. Os princípios de primeira ordem dizem respeito à própria essência do político, ou seja, fundada nas relações de poder e no antagonismo. Como elementos ontológicos, devem ser levados em consideração para toda e qualquer teoria política calcada no princípio da realidade. 0 princípio de segunda ordem é a idéia central da teoria agônica, ou seja, a transformação das 
relações antagônicas em agônicas, a substituição da categoria de inimigo pela de adversário, o que é muito interessante, sem dúvida. No entanto, o seu modelo incompleto pára por aí. Mouffe não desenvolve mais o pluralismo agonístico, no sentido da proposição de instituições, quem sabe um novo tipo de parlamento que trate de questões políticas culturais originalmente não-econômicas, arenas de lutas institucionalizadas etc. Mouffe enuncia um princípio que abre várias possibilidades para se pensar a democracia contemporânea. Entretanto, como 0 dia-a-dia da política ocorre na dimensão ôntica, é preciso pensar instituições ou práticas políticas efetivas que façam valer o princípio agonístico.

\section{NORVAL: É POSSÍVEL UM DIÁLOGO ENTRE DELIBERATIVOS E PÓS-ESTRUTURALISTAS?}

Aversive Democracy é um interessante esforço de Aletta Norval no sentido de promover um diálogo, ao mesmo tempo, com o modelo deliberativo, sobretudo habermasiano, e com as teorias pós-estruturalistas da política de Laclau, Mouffe, Rancière, Zizek, entre outros. Mesmo considerando a dificuldade de tratar homogeneamente diversas perspectivas teóricas simplesmente pelos rótulos deliberativos e pós-estruturalistas, Norval busca construir este diálogo a partir de grandes linhas que, em geral, seriam acordadas pelos autores que ela associa a ambos os esforços. Por exemplo, em termos de uma perspectiva deliberativa da democracia, de inspiração habermasiana, a autora afirma que alguns parâmetros gerais podem ser considerados, como segue:

Em contraste com as concepções adversariais da democracia, ela [a perspectiva deliberativa] coloca grande ênfase na busca de acordos consensuais. Em contraste com modelos agregativos de democracia, ela se foca na formação de opiniões, interesses e desejos democráticos. [...] Acordos alcançados sob condições especificadas têm 0 poder de legitimar instituições e princípios políticos de um modo que a simples soma de votos não faz, visto que põe os cidadãos sob um requerimento de publicidade: eles devem oferecer razões para as suas posições e reivindicações e devem defender estas razões publicamente (NORVAL, 2007, p. 21-22).

Se o esforço deliberativo de inspiração habermasiana apresenta, em geral, as características acima apresentadas, a autora sintetiza o esforço pós-estruturalista a partir de outros princípios, ou seja, os pós-estruturalistas buscam entender 0 político desde uma perspectiva ontológica. Neste sentido, para tais autores, as 
relações políticas devem considerar necessariamente: 1) as relações de poder; 2) a ideia de que qualquer acordo ou decisão política, mesmo tornando-se hegemônica, está sempre tendente a ser desafiada futuramente; 3) as mais amplas formas de argumentação política, além do discurso racional, devem ser consideradas e; 4) enfatiza-se justamente o desacordo, em detrimento do consenso, como princípio da democracia. Segundo Norval, as diferenças entre ambas as tradições podem ser resumidas da seguinte forma:

Há três áreas-chave nas quais os teóricos da democracia radical muito marcadamente se diferenciam. A primeira refere-se ao objetivo da argumentação democrática. Como acima dito, para os teóricos deliberativos, o objetivo é a busca de um consenso racional. Isto marca um forte contraste com os democratas radicais da tradição pós-estruturalista que estão preocupados com o potencial conflituoso e deslocatório da democracia. Segundo, enquanto as concepções deliberativas da democracia partem de um modelo de diálogo sem constrangimento, desprovido do poder e das 'distorções', os pós-estruturalistas argumentam que as relaç̧ões de poder são intrínsecas às suas abordagens acerca da democracia. Finalmente, em contraste com o projeto habermasiano, os pós-estruturalistas não pretendem especificar pré-condições normativas e fundações para o discurso democrático (NORVAL, 2007, p. 38-39).

A última diferença elencada por Norval, ou seja, a não especificação de condições normativas para o discurso democrático, em nossa análise, parece ser o ponto de diferenciação mais importante entre as duas tradições. Neste ponto, entende-se que ambas apostam em sentidos absolutamente contrários e isso justifica, em parte, as limitações normativas no trabalho de Mouffe, como acima demonstrado.

Mesmo considerando que as duas primeiras diferenças apontadas são também importantes - ou seja, de um lado se pretende o consenso racional e de outro isso se mostra como uma impossibilidade; do lado dos deliberativos, busca-se reduzir ao máximo o poder enquanto que, do lado pós-estruturalista, o poder justamente é visto como constituidor das próprias relações políticas e sociais e, portanto, inerradicável - o fato de os pós-estruturalistas não apresentarem cenários políticos normativos tem a ver com a assunção de que qualquer projeto normativo será sempre incapaz de dar conta de toda a complexidade das relações humanas. Todas as características do político, na perspectiva pós-estruturalista, não são, ao contrário do enfoque deliberativo, normativas. Tais elementos refletem 
justamente a ontologia do político, ou seja, fazem parte de reflexões do ser político enquanto tal. Isto quer dizer que qualquer proposta política normativa deve levar em consideração tais elementos para que a mesma seja passível de êxito real. Tomando em consideração a ontologia do político, segundo os pós-estruturalistas, 0 enfoque deliberativo propõe um modelo, entendido aqui somente em seus aspectos mais gerais, fadado ao fracasso, por não considerar estes elementos ontológicos. Dito de outra forma: o grau de idealismo presente na perspectiva habermasiana contrasta fortemente com um princípio de realidade política apresentado pelos pós-estruturalistas.

Em termos mais específicos, as diferenças entre os enfoques são ainda mais claras. Vejamos, por exemplo, como cada perspectiva trata do tema da igualdade política. Mesmo ambas obviamente entendendo o papel fundamental que a igualdade tem para a democracia, elas divergem claramente sobre o seu conteúdo. Segundo Norval, para os deliberativos a condição de igualdade está ancorada basicamente num "guia normativo que deve informar não apenas a estrutura dos próprios argumentos, mas também os espaços nos quais eles devem aparecer" (NORVAL, 2007, p. 65). À igualdade é dada uma ênfase procedimental, no sentido de que só há igualdade política no momento em que todos os participantes têm idênticas condições de expor os seus argumentos, de propor temas e de serem efetivamente capazes de influenciar no resultado da deliberação.

Toda a ênfase no procedimento para que este garanta condições de igualdade de participação e de influência a todos visa a isolar as relações de poder que claramente desequilibrariam um processo deliberativo. Neste mesmo espírito de redução da desigualmente inerente às relações de poder é que a linguagem ganha centralidade no discurso deliberativo. Aqui Norval identifica duas gerações de autores desta tradição. A primeira geração atribui à razão a supremacia para o discurso democrático. A segunda geração questiona o racionalismo excessivo defendido pela primeira geração, buscando escapar às condições idealizadas de comunicação para instâncias reais de contestação democrática. Norval se coloca, por razões que veremos na seção seguinte, muito mais próxima da segunda geração. Contudo, mesmo esta "não está preparada para questionar a hierarquia estabelecida entre, de um lado, formas retóricas tais como o testemunho, a história contada etc. e a argumentação racional de outro (NORVAL, 2007, p. 67). Segundo Norval, isso seria necessário justamente tendo em vista que tais trabalhos buscam enfocar processos reais de argumentação democrática. Assim, apesar de a segunda geração de autores avançar nas possibilidades para se pensar o processo 
deliberativo, visando às situações reais, "as formas alternativas de expressão que são consideradas fora do padrão são sistematicamente subordinadas em relação ao que é tratado como o padrão, nomeadamente, a argumentação racional" (NORVAL, 2007, p. 67)². A razão é, para os deliberativos, redundantemente, a ultima ratio para a deliberação democrática, entendida como a forma padrão para garantir um nível razoável de igualdade entre os participantes. A igualdade, neste sentido, é procedimental; uma vez criado o espaço para as discussões democráticas, qualquer indivíduo, desde que consciente das regras do mesmo, pode participar, propor e influenciar o resultado.

Já a noção de igualdade política, para os teóricos pós-estruturalistas, é outra. Se os deliberativos acreditam que a igualdade política é possível de ser alcançada a partir da instituição de espaços próprios de deliberação não-coativos, para os pósestruturalistas o problema é outro, ou seja, este espaço precisa ser construído. Isso quer dizer que mesmo que o espaço deliberativo busque abarcar toda e qualquer diferença política, ele sempre será excludente, sempre haverá identidades de fora do mesmo. A discussão dos pós-estruturalistas sobre a igualdade, portanto, não está direcionada a quem está incluído no espaço de deliberação, pois que está voltada justamente para quem não tem acesso ao mesmo. Segundo Norval (2007, p. 78):

[...] não há primeiro um espaço partilhado no qual todas as razões e demandas podem ser igualmente ouvidas e que novas demandas podem ser inscritas, mas antes este espaço partilhado de razões precisa ser instituído, através de outras práticas além da argumentação verbal. Assim, a verificação de pressuposição da igualdade sempre tem lugar através de uma ruptura de uma ordem dada por desentendimentos (mésentente), que desafiam ordens existentes e instituem novos espaços de sentido, os quais podem tornar-se locais de emancipação ou, alternativamente, podem se tornar ossificados pelo tempo.

Neste sentido, o argumento de Jacques Rancière (1996) é exemplar. Este autor dá o exemplo da resistência e da intransigência dos patrícios em torno das demandas políticas dos plebeus. Tal postura derivava-se de um nãoreconhecimento por parte dos patrícios de que os plebeus detinham o dom da fala:

\footnotetext{
${ }^{2}$ Norval exemplifica Dryzek (2000) como um autor vinculado à segunda geração de deliberativos que, mesmo considerando outras formas de argumentação, subordina as mesmas ao argumento racional.
} 
"não há por que discutir com os plebeus, pela simples razão de que estes não falam. E não falam porque são seres sem nome, privados de logos, quer dizer, de inscrição simbólica na polis" (RANCIÈRE, 1996, p. 37). Assim, a luta dos plebeus não era por ocupar os espaços políticos existentes, pois os mesmos eram estranhos a eles, não os incluíam, uma vez que as linguagens eram completamente incompatíveis. A solução que os plebeus encontraram, segundo Rancière, foi a instituição de "uma outra ordem, uma outra divisão do sensível" (RANCIÈRE, 1996, p. 37-38). A partir de então, vendo que os plebeus possuíam fala, não restou alternativa aos patrícios: eles teriam de falar com os plebeus. A questão da igualdade política não está, portanto, na simples construção de pretensos espaços comuns para tomada de decisões públicas, visto que a questão é ainda anterior. Os espaços são inclusivos e excludentes ao mesmo tempo e a luta política da igualdade é a luta pela inclusão. Nas palavras de Rancière (1996, p. 40):

A política é primeiramente o conflito em torno da existência de uma cena comum, em torno da existência e a qualidade daqueles que estão ali presentes. É preciso, antes de tudo, estabelecer que a cena existe para o uso de um interlocutor que não vê e que não tem razões para vê-la já que ela não existe. As partes não preexistem ao conflito, que elas nomeiam e no qual são contadas como partes. [...] Existe política porque aqueles que não têm direito de ser contados, e instituem uma comunidade pelo fato de colocarem em comum 0 dano que nada mais é que o próprio enfrentamento, a contradição de dois mundos alojados num só: o mundo em que estão e aquele em que não estão, o mundo onde há algo "entre" eles e aqueles que não os conhecem como seres falantes e contáveis e o mundo onde não há nada.

Neste momento, é importante fazer referência à distinção que Rancière faz entre polícia e política. Polícia é o momento da ordem, da instituição de uma regra, aquilo que é possível ser dito, pois já regrado e visto como discurso, ao contrário do ruído. Assim, os patrícios tinham a polícia instituída e esta, por sua vez, não admitia, pois que estavam fora da regra e fora do discurso, a presença dos plebeus, aqueles que emitiam somente ruído. Por outra parte, a política é 0 instante do rompimento desta ordem; "ela faz ver o que não cabia ser visto, faz ouvir um discurso ali onde só tinha lugar o barulho, faz ouvir como discurso o que só era ouvido como barulho" (RANCIÈRE, 1996, p. 42). Tendo em vista a distinção entre polícia e política de Rancière, o tema da igualdade toma diferentes contornos. Segundo Norval (2007, p. 77): 
Assim, a igualdade não é uma substância aparte da prática que a verifica. E 0 que faz uma ação policial não é o seu objeto, nem como os teóricos deliberativos mantêm o lugar onde ela é levada a efeito, mas a sua forma, que é aquela constituída numa disputa. Nada é político em si; torna-se assim apenas onde a luta entre a ordem da polícia e uma ordem igualitária se coloca, reconfigurando, desta forma, as relações.

Neste sentido, parece evidente afirmar que toda a luta política é uma luta por igualdade. A política só faz sentido e só tem evidência quando o sentimento de desigualdade está presente. Não há em si um tema eminentemente político, assim como não há a constituição de um grupo político anterior à irrupção de uma demanda por igualdade, por inclusão. Partindo deste pressuposto, constituir espaços privilegiados para discussão e deliberação de questões a ser publicizadas não geraria necessariamente uma condição de igualdade. Pode, ao contrário, tendo em vista toda uma série de constrangimentos linguísticos - sobretudo, por um imperativo do exclusivo uso da razão - servir mais como um exemplo de sedimentação da polícia, necessitando-se, portanto, de uma reativação política.

Tendo em vista o que até agora foi dito, a distância que se coloca entre as tradições deliberativa e pós-estruturalista da democracia, a partir das distintas noções de igualdade, faz das mesmas teorias praticamente incompatíveis. No entanto, o esforço de conciliar elementos de uma ontologia pós-estruturalista do político e condições institucionais de comunicação para a tomada de decisões públicas, a partir de uma perspectiva deliberativa, já foi uma preocupação, pelo menos implícita, expressa no trabalho de Chantal Mouffe. Apesar desta preocupação, sobretudo, na proposição do seu "modelo" agonístico de democracia, Mouffe não consegue ir além da enunciação de um princípio. Mesmo considerando toda a série de constrangimentos epistemológicos e ontológicos presentes na tradição pós-estruturalista da democracia radical, entende-se que 0 esforço de Norval em direção de uma democracia aversiva merece ser levado em consideração. Nas próximas seções, veremos quais são os pressupostos centrais de tal empreendimento teórico.

\section{A POLÍTICA DO ORDINÁRIO E A MUDANÇA DE ASPECTO}

Mesmo considerando as claras diferenças epistemológicas entre as perspectivas pós-estruturalista e deliberativa, Norval tenta articulá-las na construção da sua proposta teórica. Inicialmente, deve-se mencionar que a autora 
está escrevendo a partir de uma vinculação muito mais evidente com a perspectiva pós-estruturalista, tendo em vista, sobretudo, a autora possuir trajetória acadêmica ligada a esta tradição. Em vários momentos do livro, ela considera que este enfoque é superior ao deliberativo e isto se reflete no que é central as suas preocupações com o desenvolvimento de uma teoria democrática mais próxima do ordinário, ou seja, do cidadão comum e das práticas reais de tomada de decisões públicas. Assim, ao mesmo tempo em que Norval entende que há a necessidade de espaços deliberativos para tomada de decisões democráticas, tais espaços devem considerar condições reais e acessíveis para a efetiva participação das pessoas. Neste sentido, a autora afirma:

[...] o objetivo deste exercício, embora teórico, não é produzir uma abordagem do discurso democrático que esteja abstraída do 'fluxo da vida' e removida de todo e cada contexto. Não está aqui pressuposto que as gramáticas políticas em geral e as formas democráticas de argumentação em particular poderiam ou deveriam ser abstraídas de contextos ordinários e de interesses e de paixões que inspiram o engajamento na política democrática em primeira instância. Este desejo de separar a política das preocupações do ordinário geralmente provém de uma negação platônica da retórica e de uma valorização excessiva das reivindicações da razão (NORVAL, 2007, p. 61-62).

A ideia da razão como condutora dos processos deliberativos, para a autora, deve ceder espaço a um conceito de argumentação que, ao mesmo tempo, a abrange e a excede. Norval inspira-se na ideia de entendimento presente na filosofia de Wittgenstein, que a considera como uma atividade prática e que possui uma importante dimensão de "mostrar", de exemplificar, o que escapa ao uso estrito da razão dedutiva. 0 raciocínio, portanto, está além do uso da razão. Para Norval, aliás, há a necessidade de rediscutir a dicotomia razão/retórica, buscando valorizar a segunda. ${ }^{3}$

\footnotetext{
${ }^{3}$ Neste ponto, a autora não faz mais do que reproduzir uma ideia-força presente na tradição pós-estruturalista. Para Laclau, por exemplo, "a retórica não é um epifenômeno em relação a uma estrutura conceitual autodefinida, já que nenhuma estrutura conceitual encontra sua coesão interna sem apelar a recursos retóricos" (LACLAU, 2005, p. 91). Isto quer dizer que toda constituição identitária se faz a partir também da utilização de recursos retóricos no sentido mais amplo do termo, ou seja, na busca pela persuasão e pelo convencimento de seu discurso (REBOUL, 2000), tendo em vista uma dimensão hegemônica (que é uma dimensão em grande medida alcançada pelo uso da retórica) presente nas estratégias de identidades democráticas. Neste sentido, para Laclau e Mouffe (1985), a possibilidade de uma identidade democrática universalizar seu discurso se dá justamente pela tentativa de hegemonização e é, neste momento, que a retórica ganha centralidade.
} 
Portanto, tendo em vista uma clara valorização da retórica, Norval busca mostrar a importância da analogia, da comparação, do exemplo. "Mostrar" algo é revelar uma dimensão argumentativa, é trazer uma novidade e até mesmo, revelar o surpreendente. Contudo, este "mostrar", esta argumentação analógica não deve ser entendida, obviamente, como um exemplo a ser copiado, uma vez que, para a autora, este tipo de recurso retórico não pressupõe uma transposição descontextualizada de práticas. Defender algo do gênero seria uma completa contradição com uma das ideias centrais da autora, qual seja, a de produzir uma teorização democrática que se aproxime e que seja inspirada nas próprias práticas políticas ordinárias. Isto fica evidente nas características da argumentação por analogia apresentadas por Norval, num total de quatro: $1^{\circ}$ ) provém de um caso paradigma ou precedente; $2^{\circ}$ ) é contextual e de audiência específica; $3^{\circ}$ ) não pressupõe generalizações e; $4^{\circ}$ ) envolve estender ao que é novo e não familiar a partir de graus ou estágios.

A partir das características da argumentação pela analogia, é conveniente introduzir a noção de "mudança de aspecto" (aspect change), oriunda da filosofia de Wittgenstein, e que, segundo Norval, pode ser uma importante contribuição para a argumentação democrática, mantendo-se a preocupação central desta autora em direção de uma democracia do ordinário. A mudança de aspecto nos revela uma nova percepção sobre um objeto, o qual estamos acostumados a ver de uma mesma forma. Um olhar diferente sobre este objeto nos revela um novo "aspecto" que anteriormente não havia sido percebido. Conforme Glock (1998, p. 51), "é assim que deixamos de ver um 'enigma gráfico' como um amontoado de linhas e passamos a vê-lo como um rosto; ou deixamos de ver o 'coelho-pato' de Jastrow como o desenho de um pato, e passamos a vê-lo como o desenho de um coelho". ${ }^{4}$

Norval incorpora a mudança de aspecto, contudo promovendo uma diferença entre esta noção e a de "iluminação de aspecto" (aspect dawning). A autora afirma que a segunda não está claramente identificada na filosofia de Wittgenstein como uma distinção em relação à mudança de aspecto, mas que

\footnotetext{
${ }^{4}$ Ainda, segundo Glock (1998, p. 51), "Wittgenstein conferiu uma importância enorme à percepção de aspectos, uma vez que acreditava que esses fenômenos 'nos fazem pensar em problemas relativos ao conceito de visão' (LW I § 172). Isso se deve, possivelmente, ao fato de que ele ilustra, de forma precisa, a natureza conceitualmente saturada da percepção. Vemos uma única coisa (por exemplo, o rosto de alguém), mas podemos vê-la de diferentes formas (por exemplo, tranqüilo ou angustiado)".
} 
há suficientes indícios no desenvolvimento original desta categoria para que ela perceba uma importante diferença entre estas noções. Na verdade, iluminação de aspecto e mudança de aspecto são dois momentos diferentes, porém interligados, de uma mudança de percepção de objetos e, ainda mais, da relação entre objetos. Para Norval (2007, p. 134):

Se iluminação de aspecto implica o novo, aquele elemento de surpresa inicial, quando uma nova série de conexões ou articulações nos oferece um quadro que nos permite ter uma experiência de ruptura, a mudança de aspecto pode ser usada para capturar o sentido no qual o momento inicial da iluminação poderia ser reativado num último estágio.

Para a autora, diferenciar estas duas dimensões produz consequências importantes para a constituição de subjetividades políticas. A ideia da iluminação de aspecto contém o elemento da surpresa, da imediata percepção do novo, algo que, de fato, estava ali, mas que não havia sido percebido. Norval, neste ponto, dá como exemplo o momento em que alguém assume uma subjetividade democrática: "Agora eu sou um democrata!" (NORVAL, 2007, p. 134). Já a mudança de aspecto envolve a dimensão da reativação, ou seja, lembrar-se novamente o porquê de se ser um democrata. Esta lembrança mobiliza, ao mesmo tempo, a inovação da iluminação de um novo aspecto, mas também é necessária a reativação da ideia da razão de se ser um democrata constantemente. Isso não se dá simplesmente por uma troca de argumentos, mas pela recorrência de práticas políticas que indicam tal condição. Norval é absolutamente clara neste sentido:

Tornar-se um democrata (novamente) não é para ser entendido na base de um modelo cognitivo. Não é suficiente o argumento de que para superar 0 déficit democrático simplesmente precisamos 'educar' melhor os cidadãos. É também porque não é suficiente pensar que simplesmente apresentar 'os fatos de um caso' num contexto rarefeito fará de todos democratas. Democratas precisam tornar-se democratas, repetidamente, e isto requer identificação e persuasão. É aqui, como sugeri, que o papel da persuasão e da retórica tornase central para qualquer explicação da subjetividade democrática. A importância do consentimento por parte do sujeito não deve ser também subestimada. No entanto, como argumentei, tal consentimento não deve ser entendido principalmente na base de um modelo racional de razão-dada. Uma das contribuições-chave do último Wittgenstein é a sua ênfase para ver as coisas corretamente. A habilidade do sujeito para ver novas conexões e para imaginar uma nova gramática política contaria aqui como evidência de seu consentimento (NORVAL, 2007, p. 139). 
Iluminação e mudança de aspecto envolvem primordialmente a ideia de identificação de um sujeito a partir da mudança de percepção de determinada situação política. Tal identificação é fundamental para a construção de subjetividades democráticas em processos reais de disputas políticas. A partir da constituição de subjetividades políticas é que podem ser construídos espaços para discussões e para a busca de soluções para questões políticas que emergem. Na seção seguinte, ver-se-á como estas categorias podem ser úteis no modelo da democracia aversiva.

\section{NORVAL E A AVERSÃO AO CONFORMISMO DEMOCRÁTICO}

Nesta seção, será apresentada a noção de democracia aversiva. Se na seção anterior, as ideias da política do ordinário e da valorização da retórica tiveram centralidade - com especial ênfase às categorias de mudança de aspecto e de iluminação de aspecto, no sentido de que as mesmas são instrumentos importantes para a argumentação, a exemplaridade e o convencimento democráticos - a partir de agora serão vistos mais claramente os elementos normativos do enfoque democrático de Aletta Norval. Articular tais elementos normativos significa mover-se justamente no centro da areia movediça que é a discussão entre pós-estruturalistas e deliberativos. Se do lado dos primeiros existe um claro déficit normativo em torno de propostas que visam ao aprimoramento da qualidade dos debates e das decisões democráticas, o qual se justifica especialmente por uma concepção ontológica do político presente nesta tradição, do lado dos deliberativos, o problema reside no fato de que os seus esforços normativos não levam em consideração tal ontologia, o que faz com que Norval, em geral, rejeite as suas soluções, visto que as mesmas estão descoladas de uma preocupação com as práticas políticas reais, cotidianas, ordinárias. Segundo Norval, os limites de ambas as tradições são entendidos como segue:

Os pós-estruturalistas tendem a trabalhar com uma nítida distinção entre 0 momento do político, que é geralmente entendido em termos de instituição de regimes, e a política do dia-a-dia, em que a última é relegada em favor do primeiro. [...] [E]sta tendência tem consequências negativas importantes para as suas teorias democráticas, pois coloca entre parêntesis questões normativas e enfatizam, de forma exagerada, o político como deslocamento e ruptura. Como consequência, a gramática da política democrática em curso permaneceu, em grande medida, não analisada e sub-teorizada. Em 
contraste, as teorias deliberativas falham em relação à instituição e à formação real de uma subjetividade democrática, negligenciando esta em favor de um modelo muito abstrato de deliberação e de procedimentos nas democracias existentes (NORVAL, 2007, p. 11-12).

Assim, entre gregos e troianos, a autora alia a ontologia pós-estruturalista à necessidade de propor elementos normativos tão caros à tradição deliberativa. Neste particular, é importante, inicialmente, destacar o sentido de democracia aversiva. A proposta de Norval, ou como ela mesma afirma, a sua gramática política, parte da ideia de uma aversão ao conformismo, não somente ao conformismo com as atuais práticas democráticas, mas também com as próprias teorias democráticas contemporâneas. A consequência disso para Norval, partindo para noção de conformismo de Cavell, autor que juntamente com Derrida será central para a sua gramática democrática, é que "o conformismo faz de nós escravos" (NORVAL, 2007, p. 7). Neste sentido, o esforço da autora é o de apresentar um enfoque teórico preocupado em renovar tanto as práticas democráticas como também a própria teoria democrática. ${ }^{5}$

Neste sentido, o ponto de partida da democracia aversiva está na importância dada à identificação do sujeito democrático. Tal identificação, na verdade, pressupõe a constituição deste sujeito como democrático e este movimento representa uma reivindicação por igualdade, uma reivindicação pelo reconhecimento de se ser parte de um processo de tomada de decisão política. Note-se que isso não significa simplesmente demandar ser parte de uma instância de discussão e de deliberação pública já existente, com regras fixadas a priori. A demanda política vai além: ela requer a discussão de regras de como a discussão e a solução da questão terão lugar. Neste ponto, Norval está sendo influenciada pelas teorias de Rancière e de Laclau:

Argumentei que a identificação é importante para a constituição do sujeito democrático e é aqui que a emergência de novas reivindicações, assim como

\footnotetext{
${ }^{5}$ No entanto, é fundamental ressaltar que a pretensão da democracia aversiva não é a de revolucionar nem as práticas nem as teorias contemporâneas. A autora está absolutamente consciente para o fato de que é preciso reunir "tradição" e "originalidade" em sua proposta. Nesta perspectiva, existe, por um lado, um conformismo a ser questionado, mas, por outro lado, uma série de princípios democráticos e de práticas políticas que devem ser preservados, reativados e, além disso, conhecidos. Assim, se há a necessidade de alterar a gramática democrática, isso não significa que não existam experiências políticas que possam iluminar ou mudar aspectos de questões políticas reais outras e que, por isso, merecem ser conhecidas.
} 
diferentes formas de relações constituídas entre sujeitos democráticos têm recebido atenção. Rancière e Laclau promovem o ponto de partida aqui. Eu tomei de Rancière a ideia da irrupção de novas demandas e a consequente reformulação de espaços 'comuns' de argumentação e de Laclau a descrição dos mecanismos através dos quais reivindicações são universalizadas (através da constituição de cadeias equivalenciais) (NORVAL, 2007, p. 187-188).

A noção de Rancière sobre a irrupção de novas demandas já foi tratada neste artigo e, portanto, não precisa ser neste momento retomada. Contudo, ainda não foi formalizada a maneira como Laclau percebe a emergência de sujeitos democráticos, a qual é importante para a teoria de Norval e que, por essa razão, a mesma será aqui brevemente abordada. ${ }^{6}$

Para Laclau (2005), toda demanda política é uma demanda por inclusão, uma vez que sua constituição necessariamente pressupõe exclusão. Tal demanda deve ser entendida, conforme o autor, como sendo "democrática" ou isolada, não se devendo aí entender qualquer conotação normativa em direção a este regime. Segundo Laclau, é absolutamente claro que a demanda "permanece em um plano estritamente descritivo" (LACLAU, 2005, p. 158). Neste sentido, Laclau está bem próximo da ideia de Rancière em torno da irrupção de novas demandas. No entanto, Laclau não acredita que uma demanda isolada possa alcançar algum nível de inclusão, se a mesma não for contemplada em termos institucionais, a não ser que esta se articule com outras demandas num sentido de que todas constituam uma cadeia de equivalências que desafie o próprio sistema institucional. Esta cadeia de equivalências, tendo como corte antagônico a instituição, a ordem estabelecida, é o momento em que Laclau chama de o momento do político.

Este momento promove um deslocamento no sistema, ou seja, uma desestruturação do mesmo, tendo em vista que, na forma como está estruturado, ele não consegue responder a esta ameaça. É necessário que o mesmo se reestruture, a partir desta experiência de deslocamento, para que ele possa novamente garantir a ordem. Este movimento articulatório é importante para a teoria de Norval, com a ressalva de que a consequência do deslocamento não seria necessariamente revolucionária:

0 deslocamento de uma dada gramática, ocorrido, por exemplo, a partir da articulação de novas demandas - aquelas demandas que não encontram

\footnotetext{
${ }^{6}$ Maiores detalhes acerca da lógica da constituição de identidades políticas segundo a teoria do discurso de Ernesto Laclau podem ser encontradas em Laclau e Mouffe (1985), Laclau (1990) e Laclau (2005).
} 
expressão em vocabulários políticos disponíveis - ou a reformulação de demandas já existentes em novas direções, é uma precondição para pensar sobre a transformação de uma gramática política. Agora, como já argumentei, deslocamento e mudança não precisam ser tematizados na base de um modelo nem de um caos revolucionário, em que tudo muda, ou a partir de uma mudança conservadora, em que, supostamente, nada muda (NORVAL, 2007, p. 189).

Apartirda experiência de um evento de deslocamento, abre-se a possibilidade para a mudança da estrutura, para a inclusão de demandas excluídas, no sentido de Laclau (2005). Para Norval, além desta possibilidade, abre-se também outra, a da imaginação democrática e, neste sentido, "é aqui que os exemplos [...] vêm para desempenhar seus papéis na vida democrática contemporânea" (NORVAL, 2007, p. 190) ${ }^{7}$. É evidente que tais exemplos provêm de situações específicas e que não podem simplesmente ser seguidos. No entanto, eles se constituem em alternativas para novas estratégias políticas, para se imaginar novas soluções e também para cultivar um "ethos democrático" (NORVAL, 2007, p. 190).

0 exemplo que Norval apresenta é o da Comissão de Verdade e Reconciliação (Truth and Reconciliation Commission - TRC). Tal Comissão, formada no contexto da transição do Apartheid, serviu para oferecer, seja a sobreviventes, seja a perpetradores de violências, oportunidades de voz para relatar, expressar arrependimento, pedir perdão pelos mais diversos atos de violência e desrespeito aos direitos humanos que tiveram lugar ao longo do regime autoritário sul-africano. Conforme Norval, a Comissão de Verdade e Reconciliação deu a oportunidade de "articular experiências passadas, perdas e traumas e, no processo, trabalhar na direção de uma transformação das relações entre os cidadãos da nova África do Sul" (NORVAL, 2007, p. 199). A autora tem claro que não devem ser superestimados os efeitos e os resultados alcançados pela TRC e que a mesma sofreu severas críticas acerca de sua pertinência. ${ }^{8}$ Contudo, o oposto, ou seja, a importância daquela no contexto da transição sul-africana não deve também ser subestimada. Mesmo considerando as limitações em termos de um processo dialógico que, conforme

\footnotetext{
${ }^{7}$ Ainda, conforme Norval (2007, p. 190), no mesmo sentido do que já foi enfatizado neste trabalho, "estes exemplos, 'manifestando de outra maneira', são sempre singulares e, em sua singularidade, eles facilitam vislumbrar um universal, outra forma de fazer as coisas".

${ }^{8}$ Parte das críticas, segundo Norval, dizia respeito a uma ingênua visão de comunicação no ambiente da Comissão que presumia uma relação transparente entre falar e restaurar a dignidade da vítima, o que de fato era questionável.
} 
Norval, presumia uma visão ingênua de comunicação, este foi um momento real em que foi dada voz a quem até então não tinha voz num contexto repressivo. ${ }^{9}$

É importante ressaltar que a experiência da Comissão de Verdade e Reconciliação está diretamente ligada à ideia da exemplaridade, ou seja, processos reais podem iluminar e mudar aspectos de outras experiências políticas. Entretanto, não menos importante é lembrar que um processo exemplar não pode ser seguido de forma simplista, visto que ele está imerso num ambiente geográfico e político muito específico. Portanto, o objetivo de Norval de apresentar esta experiência está na sua própria exemplaridade, ou seja, um processo político real, que deu voz aos cidadãos comuns, que foi constituído a partir de um contexto de contestação e de deslocamento num determinado momento da história da África do Sul e que pode servir para outros processos políticos. Segundo Norval (2007, p. 209):

$\mathrm{Na}$ tentativa de corresponder a esta responsabilidade, vivendo aversivamente, não há regras que podem simplesmente ser seguidas, não há receitas prontas para o engajamento político, não há uma série de instituições prontas em que nelas este deve ocorrer. No entanto, os exemplos devem, como disse, nos fornecer algum guia para a nossa conduta, guia ao qual, contudo, deve ser tomado de certa forma.

A partir do exemplo da Comissão de Verdade e Reconciliação, chega-se ao último ponto da proposta da democracia aversiva. Este ponto está diretamente ligado à relação entre a exemplaridade e a imaginação democrática, vistas como ingredientes aversivos para vencer o conformismo, seja com as práticas democráticas atuais, seja com a própria teoria democrática contemporânea. Neste momento, Norval associa-se aos princípios do "perfeccionismo" de Cavell e da "democracia por vir" de Derrida.

0 perfeccionismo é principal inspiração de Norval, tendo em vista que a exemplaridade destacada pela autora é oriunda desta noção. Para Cavell, o perfeccionismo é um pensamento aversivo, inconformado com o atual estágio da

\footnotetext{
${ }^{9}$ Segundo Norval: "não se deve subestimar o que foi alcançado durante o período de transição. Enquanto está claro que a TRC apenas iniciou o que necessita ser um processo em curso em muitos níveis e muitas áreas da vida, é possível discernir um número de áreas nas quais ele deu uma contribuição duradoura. Estas incluem a promoção de subjetividade democrática através de um espaço dado a novas vozes e demandas; uma provocação para um debate aberto e democrático sobre questões, processos e instituições - igualmente acerca da reflexão sobre o caráter da justiça, da verdade e do papel da memória e da reconciliação em uma nova democracia" (NORVAL, 2007, p. 200).
} 
democracia. É necessário ter esta postura para superar os seus impasses. Conforme Norval (2007, p. 177), "Cavell sugere que ele [o perfeccionismo] está ligado à democracia de uma forma muito particular: como preparação da resistência às falhas da democracia, mantendo a esperança democrática viva em face de um desapontamento com esta". Já a noção derridiana da democracia por vir não apresenta nenhum elemento teleológico, ou seja, não aponta para nenhum estágio evolutivo ao qual a democracia devesse alcançar. Democracia por vir tem 0 sentido de buscar sempre garantir a abertura para a relação com 0 outro, uma promessa para com um futuro aberto a inovações e experiências, ou seja, a tarefa democrática é sempre indeterminada e incompleta. Ambas as noções estão claramente ligadas, seja como formas de perfeccionismo, seja como estruturas de promessas, mas, sobretudo, porque elas marcam um elemento fundamental para a experiência democrática como um todo. Este elemento tem a ver com a forma que devemos olhar para a democracia, ou seja, não simplesmente como um regime político, mas como um meio de vida. ${ }^{10}$

Assim, devendo tratar a democracia como um ethos e não um regime, um processo em constante formação, é que o papel da exemplaridade tem lugar de destaque. 0 exemplo, aliado a uma eterna aversão ao conformismo institucional, faz com que novas possibilidades para o debate democrático estejam sempre abertas. Desta forma, a identificação como uma identidade em busca de igualdade, a contestação e o deslocamento de estruturas existentes, a possibilidade de inclusão via novos espaços de contestação e de discussão de questões reais e que tais espaços e soluções possam iluminar/mudar aspectos, tornando-se exemplos para outras experiências, aliados à ideia do perfeccionismo e da democracia por vir, fazem com que o modelo aversivo de Norval seja uma interessante proposta teórica pósestruturalista para a democracia. Norval consegue avançar significativamente além do princípio agonístico de Mouffe, aliando a ontologia pós-estruturalista com a instituição de espaços de discussão e de decisão tão caros aos deliberativos.

\footnotetext{
${ }^{10}$ Norval é clara neste sentido: "Democracia, nestes termos, deve ser entendida como uma forma de vida em vez de um regime, a sua defesa em termos de desenvolvimento de um ethos em vez de uma série de instituições, embora isto claramente não negue a necessidade de um pensamento criativo sobre as últimas. [...] A democracia e a identidade democrática não estão dadas de uma vez por todas, plenamente constituídas e simplesmente sujeitas à administração. Ao contrário, como Cavell e Derrida deixam claro, a democracia é para ser concebida como um projeto em curso de renovação" (NORVAL, 2007, p. 185).
} 


\section{Considerações FinaIS}

Neste trabalho, buscou-se apresentar duas teorias democráticas pósestruturalistas e suas relações com o paradigma concorrente, ou seja, a teoria deliberativa. Ainda que o esforço de Mouffe tenha de ser valorizado, sobretudo no que diz respeito aos elementos ontológicos da política que deveriam guiar todos os esforços normativos, o seu autodenominado "modelo agonístico" não apresenta avanços significativos para a proposta de radicalização da democracia. Neste artigo, entende-se que Mouffe não vai além da proposição de um "princípio agonístico". Isto se deve, em parte, justamente pelos constrangimentos ontológicos que acabam limitando a autora num sentido normativo.

0 mesmo, contudo, não ocorre no caso de Norval. Aversive Democracy certamente avança em relação à proposta de Mouffe, visto que este trabalho propõe elementos normativos interessantes à radicalização da democracia, respeitando os princípios ontológicos partilhados pela tradição pós-estruturalista da teoria política.

\section{REFERÊNCIAS}

CANETTI, Elias. Crowds and power. London: Gollancz, 1962.

DRYZEK, John S. Deliberative democracy and beyond: liberals, critics, contestations. Oxford: Oxford University Press, 2000.

GLOCK, Hans-Johann. Dicionário Wittgenstein. Rio de Janeiro: Jorge Zahar, 1998.

LACLAU, Ernesto. Nuevas reflexiones sobre la revolución de nuestro tiempo. Buenos Aires: Nueva Visión, 1990. La razón populista. Buenos Aires, FCE, 2005.

LACLAU, Ernesto; MOUFFE, Chantal. Hegemony and socialist strategy: towards a radical democratic politics. London: Verso, 1985.

MOUFFE, Chantal. La paradoja democrática. Barcelona: Gedisa Editorial, 2003. . On the political. New York: Routledge, 2005.

NORVAL, Aletta J. Aversive democracy: inheritance and originality in the democratic tradition. Cambridge: Cambridge University Press, 2007.

RANCIÈRE. Jacques. $O$ desentendimento. São Paulo: Ed. 34, 1996.

REBOUL, Olivier: Introdução à retórica. São Paulo: Martins Fontes, 2000. 